\title{
Neuromuscular training in construction workers: a longitudinal controlled pilot study
}

\author{
Oliver Faude · Lars Donath • Micha Bopp • \\ Sara Hofmann • Daniel Erlacher · Lukas Zahner
}

Received: 11 March 2014 / Accepted: 20 October 2014 / Published online: 30 October 2014

(C) Springer-Verlag Berlin Heidelberg 2014

\begin{abstract}
Objective Many accidents at construction sites are due to falls. An exercise-based workplace intervention may improve intrinsic fall risk factors. In this pilot study, we aimed at evaluating the effects of neuromuscular exercise on static and functional balance performance as well as on lower limb explosive power in construction workers.

Methods Healthy middle-aged construction workers were non-randomly assigned to an intervention $[N=20$, age $=40.3(\operatorname{SD} 8.3)$ years $]$ or a control group $[N=20$, age $=41.8$ (9.9) years]. The intervention group performed static and dynamic balance and strength exercises (13 weeks, 15 min each day). Before and after the intervention and after an 8-week follow-up, unilateral postural sway, backward balancing (on 3- and 4.5-cm-wide beams) as well as vertical jump height were assessed.

Results We observed a group $\times$ time interaction for postural sway ( $p=0.002$ ) with a reduction in the intervention group and no relevant change in the control group. Similarly, the number of successful steps while walking backwards on the $3-\mathrm{cm}$ beam increased only in the intervention group ( $p=0.047$ ). These effects were likely to most likely practically beneficial from pretest to posttest and to followup test for postural sway $(+12 \%$, standardized mean difference $(\mathrm{SMD})=0.65$ and $17 \%, \mathrm{SMD}=0.92)$ and backward balancing on the $3-\mathrm{cm}$ beam $(+58 \%, \mathrm{SMD}=0.59$ and $37 \%, \mathrm{SMD}=0.40$ ).
\end{abstract}

O. Faude $(\triangle) \cdot$ L. Donath $\cdot$ M. Bopp $\cdot$ L. Zahner Department of Sport, Exercise and Health, University of Basel, Birsstr. 320B, 4052 Basel, Switzerland

e-mail: oliver.faude@unibas.ch

S. Hofmann · D. Erlacher

Institute of Sport Science, University Bern, Bern, Switzerland
Conclusions Fifteen minutes of neuromuscular training each day can improve balance performance in construction workers and, thus, may contribute to a decreased fall risk.

Keywords Balance $\cdot$ Strength $\cdot$ Falls $\cdot$ Exercise . Workplace · Safety

\section{Introduction}

Twenty to forty percent of all disabling occupational injuries in industrialized countries are related to tripping, slipping, or falling. Such incidents are the second most cause of fatal accidents (Courtney et al. 2001). In the USA, 11.3 million accidents were due to tripping, slipping, or falling (Warner et al. 2000). This corresponds to 43 falls per 1,000 persons (Warner et al. 2000), resulting in direct costs of US\$ 50-400 per person and year (Leamon and Murphy 1995). Risk factors for trip, slip, and fall-related accidents at the workplace are related to the environment (e.g., floor, lighting, and weather conditions), to workspecific duties and circumstances (working speed, carrying loads, and footwear), and to personal factors (age, sex, attention focus, and function of the sensory-motor system; Bentley and Haslam 2001; Courtney et al. 2001; Redfern et al. 2001).

The capacity of the neuromuscular system, i.e., proprioceptive/sensorimotor functioning and neuromuscular coordination, is regarded important for the maintenance of postural control and body stability in order to avoid injuries and falls (Granacher et al. 2011a; Zech et al. 2010). Inadequate muscle strength and balance performance are important intrinsic fall risk factors and may relevantly contribute to general accident proneness (Granacher et al. 2011b). Appropriate postural control mechanisms, including 
cortical control as well as spinal reflex activities, contribute to shorter latencies of lower extremity muscles during the compensation of unexpected perturbations to a stabilization of gait and to reduced postural sway while standing (Granacher et al. 2011b; Papegaaij et al. 2014). With respect to muscular strength not only maximal voluntary force production but, in particular, the rate of force development, i.e., the ability to quickly produce force is relevant to support postural control (Gruber and Gollhofer 2004; Orr 2010). Neuromuscular training programs are often multimodal and comprise a large variety of exercises, particularly from a sports performance and injury prevention perspectives (Hewett et al. 1999; Hübscher et al. 2010). Within the context of the present study, we define neuromuscular training as training to enhance proprioceptive/sensorimotor abilities and neuromuscular coordination in order to improve postural control as well as dynamic movement and joint control (Granacher et al. 2011a; Hübscher et al. 2010; Risberg et al. 2001).

Several studies have shown that specific neuromuscular training programs can increase explosive strength and jumping as well as balance performance in different populations among all age groups (Granacher et al. 2006; Taube et al. 2007, 2008; Zech et al. 2010) and can contribute to the prevention of injuries and falls (Gillespie et al. 2012; Verhagen and Bay 2010). Construction workers are a highrisk population (Chi et al. 2005; Lipscomb et al. 2006), and postural stability is considered important in challenging situations. Such situations may comprise static (e.g., standing on stilts) or functional (balancing on narrow planks) demands (Min et al. 2012; Pan et al. 2009; Simeonov et al. 2011). To the best of our knowledge, neuromuscular exercises have not been applied to prevent fall-related injuries in construction workers yet (van der Molen et al. 2012). There is one study showing that a specific neuromuscular training program which was performed over a period of 8 weeks 3 times 8 min each day relevantly improved balance and explosive strength measures in the middle-aged workforce with primarily sitting work posture (Granacher et al. 2011b). Whereas muscle strength decreased again during an 8-week detraining period, the balance adaptations were maintained or even further improved.

Based on the above-mentioned rationales and the missing scientific data in construction sites, we decided to conduct a pilot study on neuromuscular training in building workers as a proof-of-principle. Therefore, the present study aimed at evaluating the effects of 13 weeks of daily neuromuscular exercise and an 8-week detraining follow-up period on static and functional balance performance (primary outcomes) as well as on lower limb explosive power in middle-aged construction workers. It was hypothesized that the specific training program will result in improvements of static and functional balance as well as lower limb power. It was further hypothesized that the improvements in balance performance will be maintained through the follow-up period.

\section{Materials and methods}

Study design and employed procedures complied with the ethical standards of the Declaration of Helsinki. The study was approved by the local ethics committee (Ethikkommission beider Basel, EKBB, Basel, Switzerland, approval number: 391/11). All participants gave their written informed consent prior to the start of the study.

\section{Subjects}

Ninety-six healthy middle-aged construction workers were initially recruited from one Swiss construction company. Recruitment took place with support of the construction company in the region around Basel (Northwestern Switzerland). Participants were included if they were regular workers of the particular construction company and could be expected to stay in the company for at least the study period. Health status was assessed by means of the Physical Activity Readiness Questionnaire (Thomas et al. 1992). Workers with cardiovascular (coronary artery disease; prior heart attack; hypertension, $>160 \mathrm{mmHg}$ systolic, $>100 \mathrm{mmHg}$ diastolic), metabolic (diabetes mellitus), or neurological (prior stroke; neuropathy) preconditions were excluded $(N=26)$. It was a priori calculated that at least 18 participants per group are necessary to detect a moderate intervention effect $(f=0.25)$ with a statistical power of $90 \%\left(\alpha=0.05, \mathrm{G}^{*}\right.$ Power 3.1.5). As we estimated the number of workers with medical preconditions and dropout rate of at least $30 \%$, we initially tried to recruit a greater number of workers.

\section{General design}

Participants worked in teams of up to eight workers and one foreman. These teams were assigned to either an intervention (INT) or a control group (CON). Allocation was not performed randomly due to organizational constraints and practicability considerations (e.g., some teams had to be very flexible and group composition changed regularly during the study period). These teams were assigned as control groups and received no intervention. During the training period, INT performed static and dynamic balance tasks and strength exercises. Before and after the 13-week training period as well as after an 8-week follow-up period (no training), physical activity, standing balance performance, backward balancing as well as vertical jump height were assessed. 
Procedures

All tests were performed indoors under standardized conditions at the construction site at an intra-individually similar time of day in a fixed sequence as described below. Prior to all tests, a 5-minute standardized warm-up comprising joint mobilization, stretching, skipping, and hopping was conducted. Before the first test, anthropometric data as well as resting heart rate and blood pressure were obtained after a 10-min resting period in sitting position. Not all assessors were blinded with regard to group allocation.

\section{Physical activity questionnaire}

Physical activity was determined by means of the Freiburg Physical Activity Questionnaire (Frey et al. 1995). This questionnaire assesses total weekly activity (as summarized hours per week), which includes a wide range of activities for instance, baseline physical activity (e.g., daily walked or biked distance, stair-climbing), leisure time activity (e.g., hiking, dancing, bowling), and sports activity.

\section{Standing balance performance}

Static postural control was tested within $30 \mathrm{~s}$ for single limb stance with open eyes on the dominant leg. The dominant leg was determined by means of the lateral preference inventory (Coren 1993). Testing was conducted on a piezoelectric force plate measuring forces in three dimensions (anterior-posterior, medio-lateral, vertical; Kistler ${ }^{\circledR}$, 9286BA, Winterthur, Switzerland). The force plate was installed on an even floor. Total path length displacement of the center of pressure (COP) was derived from mediolateral and anterior-posterior sway. The sampling rate was $40 \mathrm{~Hz}$, and a system-immanent Butterworth filter with a low-pass cut-off frequency of $10 \mathrm{~Hz}$ was used (Donath et al. 2012). After one practice trial, participants performed three attempts for each testing condition. The best attempt was included into analysis. Workers were instructed to stand as still as possible while slightly bending their knees $\left(\sim 30^{\circ}\right)$, placing the arms akimbo and focusing with the eyes a marked spot on the wall $1.5 \mathrm{~m}$ apart. After the participants adopted the required position, data recording was immediately started. Testing was conducted without shoes, but with socks.

\section{Functional balance performance}

From a functional perspective, it is also important for construction workers to maintain postural control under dynamic conditions while working and moving their center of mass on small or unstable surfaces (Simeonov et al. 2011). In order to assess functional balance performance, participants were asked to separately perform eight consecutive backward steps without touching the ground on 4.5- and 3-cm-wide balance beams. After one practice trial, three trials with a break of $1 \mathrm{~min}$ for each beam were conducted without shoes. It was always started with the $4.5-\mathrm{cm}$ beam. The maximum amount of steps per balance beam was 24 (three trials with a maximum of eight steps without touching the ground). Total consecutive steps performed without touching the ground were recorded. Testretest reliability (Pearson's correlation) was reported to be $r=0.84$ in children (Puder et al. 2011).

\section{Vertical jump performance}

After instructions and a few practice trials, the participants performed three maximal countermovement jumps (CMJ). Between jumps, a break of 1 min was provided. Workers started in an upright position with the arms placed akimbo. They were advised to dip from the standing position and immediately jump as high as possible without resting in the squat position (Young et al. 1995). Jump performance was assessed using a vertically measuring force plate (Kistler, Quattro Jump, 9290 AD, Wintherthur, Switzerland). The sampling frequency was $500 \mathrm{~Hz}$. Jumping height was computed using the flight time method. Jumping height (h) was calculated according to the formula: $h=1 / 8 \times 9.81 \mathrm{~m} / \mathrm{s}^{2} \mathrm{t}$ (with $\mathrm{t}$ being the flight time) (Faude et al. 2011). The best attempt was analyzed.

\section{Neuromuscular training program}

The neuromuscular intervention was conducted at the workplace within the work team under guidance of the foreman. The foremen were instructed prior to the study to correctly perform and illustrate all exercises and to document attendance. Coaching of the foremen was conducted on a whole day by trained study assistants. The foremen received written information material with figures for all exercises, and they were informed about the aim of the intervention. During the 13-week training period, a total of 63 sessions were provided. Average attendance rate was $82 \%$ (SD $7 \%$ ). The program lasted 15 min each session and was conducted each work day. It was based on exercises that were previously applied in middle-aged workforce (Granacher et al. 2011b) and focused on postural control and muscle strength. Three different exercises were applied each day. In order to ensure optimal training stimuli during the whole intervention period, exercise intensity was progressively increased after four (level 2) and 8 weeks (level 3), respectively. Baseline exercises were progressively exacerbated by reducing the support base, by eliminating visual support or by increasing complexity. The foremen were reinstructed prior to each progression level. 
During these lower extremity exercises, participants had to balance a small sand-filled sack (footbag) on the foot or the head. Exercises were as follows: (1) standing balancing (one-leg stance with footbag on the other foot; in levels 2 and 3 combined with calf raises or kicking movements; $2 \times 30 \mathrm{~s}$ ); (2) dynamic balance tasks (tandem walk forth and back with footbag on one foot or the head; in levels 2 and 3 combined with calf raises and kicking movements; $2 \times 5$ steps per leg); and (3) strength exercises (bilateral calf raises with throwing the footbag in the air; in level 2 and 3 combined unilateral executions; $2 \times 10$ repetitions).

\section{Statistical analyses}

The present study was planned as a proof-of-principle trial. Thus, it was a priori decided to analyze only those participants who conducted $75 \%$ of all training sessions (per protocol analysis). Data are presented as means with standard deviation (SD). Potential baseline differences between INT, $\mathrm{CON}$, and dropouts were tested by means of a one-factorial ANOVA. In order to assess an intervention effect, we calculated a 2 (factor group: intervention vs. control) $\times 3$ (factor time: pre vs. post vs. follow-up) analysis of variance. Post hoc the Tukey test was applied. In addition, the absolute and percentage difference in the change scores between INT and CON from pretest to posttest and from pretest to follow-up test, respectively, were calculated together with $90 \%$ confidence intervals. These calculations were adjusted for pretest values to take potential baseline differences into account. A practically beneficial change was assumed when the difference score was at least 0.2 of the between-subject standard deviation (Hopkins et al. 2009). The probability for an effect being practically beneficial was calculated according to the magnitude-based inference approach using the following scale: $25-75 \%$, possibly; $75-$ $95 \%$, likely; $95-99.5 \%$, very likely; $>99.5 \%$, most likely (Batterham and Hopkins 2006). The default probabilities for declaring an effect practically beneficial were $<0.5 \%$ (most unlikely) for harm and $>25 \%$ (possibly) for benefit (Hopkins et al. 2009). Standardized mean differences (SMD) were calculated by dividing differences in means by the pretest standard deviation. Percentage changes and SMD were calculated with log-transformed data. All calculations were conducted using a published spreadsheet in Microsoft ${ }^{\circledR}$ excel (Hopkins 2006).

\section{Results}

Due to illness, injury, and occupational obligations, several participants missed tests or too much training sessions. In total, 40 construction workers were finally analyzed. Figure 1 displays the participant flow through the study.
Table 1 gives an overview of anthropometric, cardiovascular, and physical activity baseline data of all participants. There were no relevant differences in socioeconomic background and baseline parameters between INT, CON, and dropouts $(p>0.15$, Table 1$)$.

Baseline physical activity was similar between groups and remained nearly constant during the study period $(p>0.47)$. A group $\mathrm{x}$ time interaction $(p=0.002)$ in COP path length data were observed with a reduction in postural sway for INT (pretest to posttest $-7 \%$, pretest to follow-up test $-16 \%$, post hoc each $p<0.001$ ) and no significant change in CON (Table 2). We observed a group effect with higher COP path length values for CON. A group $\times$ time interaction $(p=0.047)$ was also found for the number of successful steps while walking backwards on the 3-cm-wide beam with an increase only in INT (pretest to posttest $+39 \%, p=0.03$; pretest to follow-up test $+57 \%, p<0.001)$. A time effect was observed for backwards balancing on the 4.5 -cm-wide beam with increases from pretest to posttest and follow-up tests in both groups $(p<0.007)$. Jump height was not affected.

We observed very likely practically beneficial effects from pretest to posttest for COP path length displacement and backwards balancing on the 3-cm-wide beam (Table 3). In addition, the effects for these parameters from pretest to follow-up test were most likely and likely practically beneficial. For the other parameters, the effects were possibly trivial or unclear.

\section{Discussion}

To the best of our knowledge, this is the first study that examined the effects of an exercise-based intervention on balance and jump performance in construction workers. The main result of the present study was that a 13-week neuromuscular training which was performed for $15 \mathrm{~min}$ each day resulted in practically beneficial improvements in static and functional balance performance but not in jumping height in middle-aged construction workers. The improvements in balance performance were maintained during the 8-week follow-up period. Falls are frequent occupational accidents and can lead to considerable social as well as economic consequences (Hsiao and Simeonov 2001). Postural stability has been associated with the risk of falling at construction sites (Min et al. 2012; Pan et al. 2009; Simeonov et al. 2011). The present results, thus, may contribute to a reduced fall risk in construction workers and to a decrease in accident-related costs for the individual and the employer (Gauchard et al. 2001).

Impaired balance performance which is mirrored by increased postural sway during quiet standing is associated with many health problems and, particularly, with 
Fig. 1 Participants flow through the study period

\section{$N=70$ construction worker initially assigned to}

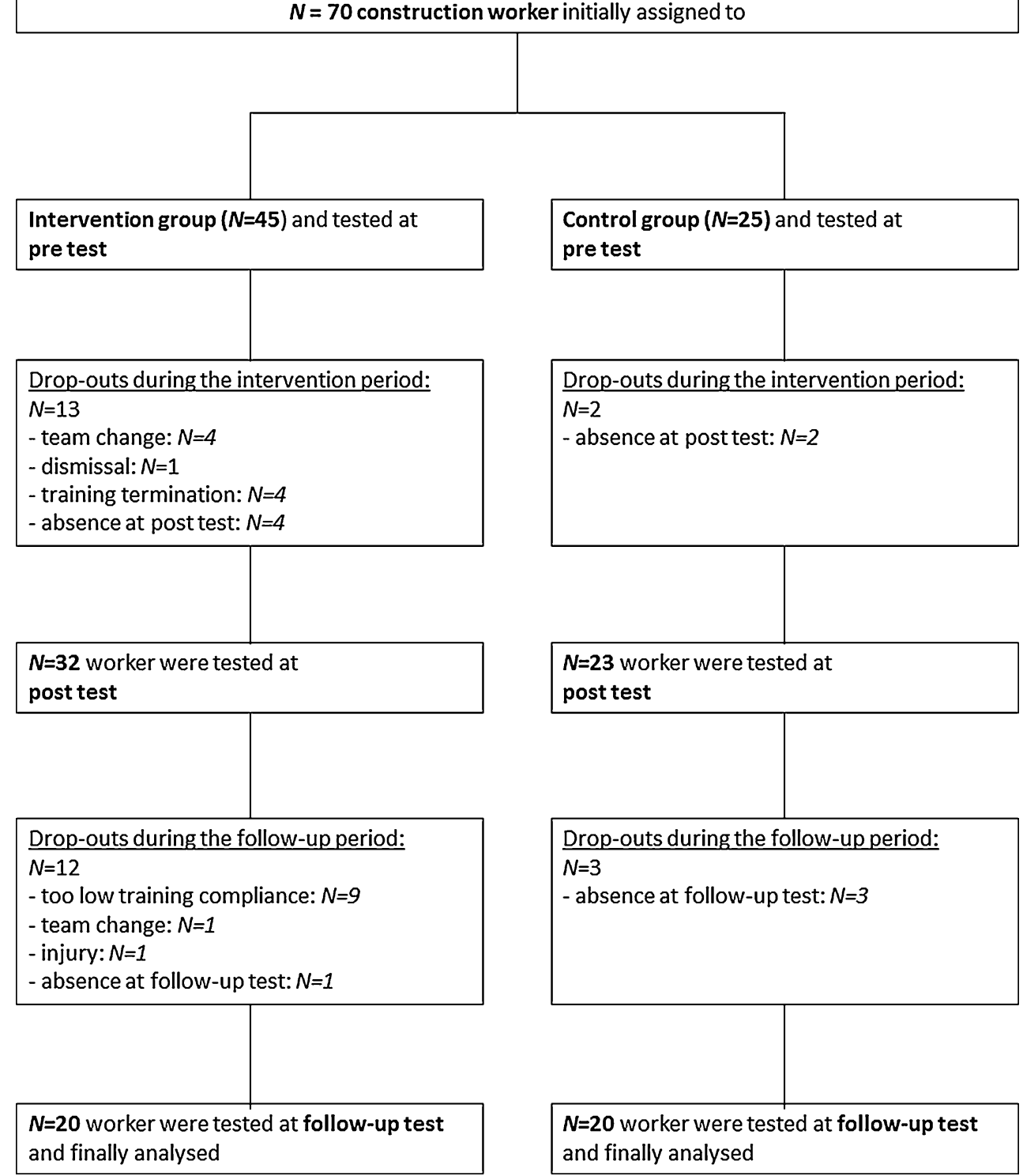

an increased risk of falling and injuries (Kiers et al. 2013; Meeuwisse 1994; Tuunainen et al. 2013). Thus, the improvements in the intervention group in the present study may contribute to a decreased fall risk in the investigated population (Min et al. 2012; Pan et al. 2009; Simeonov et al. 2011). The percentage improvements were in a similar range as recently reported in middle-aged workforce with primarily sitting work position (Granacher et al. 2011b). These adaptations were achieved with only $15 \mathrm{~min}$ of daily training. In line with Granacher et al. (2011b), we observed that these improvements were maintained through an 8-week follow-up period with no exercise training. Although the exact reasons for this observation remain speculative, the implications for practical settings seem highly relevant. In practice, different duties and obligations exist which may require flexible and short-dated changes in working routines. Reasonable time periods during which regular training is not possible do not have detrimental effects. Thus, the implementation in working routines seems feasible.

Static and functional balance performance is not necessarily correlated in middle-aged adults (Muehlbauer et al. 2011). Thus, both components of balance should be tested separately. Functional balance, as it is important while balancing in tandem walk over narrow planks or standing on instable surfaces, might be regarded more relevant from a practical viewpoint (Hsiao and Simeonov 2001; Muehlbauer et al. 2011). Backward balancing on the $4.5 \mathrm{~cm}$ wide beam was not relevantly affected. The observed improvement also in the control group might be interpreted as test familiarization. However, this was not the case for the narrower beam. Balancing on the 3-cm-wide 
Table 1 Anthropometric data, physical activity, resting heart rate, and blood pressure of the participants and dropouts at baseline

Data as means with standard deviations (in brackets)

INT intervention group, CON control group

\begin{tabular}{lccc}
\hline & INT $(N=20)$ & CON $(N=20)$ & Dropouts $(N=30)$ \\
\hline Age (years) & $40.3(8.3)$ & $41.8(9.9)$ & $39.4(11.7)$ \\
Height $(\mathrm{m})$ & $1.70(0.06)$ & $1.74(0.06)$ & $1.74(0.08)$ \\
Weight $(\mathrm{kg})$ & $82.4(10.9)$ & $83.6(12.5)$ & $86.0(16.4)$ \\
Body mass index $\left(\mathrm{m} * \mathrm{~kg}^{-2}\right)$ & $28.6(3.5)$ & $27.5(3.2)$ & $29.0(4.9)$ \\
Physical activity $\left(\mathrm{h} * \mathrm{week}^{-1}\right)$ & $6.7(5.5)$ & $5.6(5.1)$ & $6.9(6.2)$ \\
Resting heart rate $\left(\mathrm{min}^{-1}\right)$ & $73(10)$ & $78(14)$ & $76(12)$ \\
Systolic blood pressure $(\mathrm{mmHg})$ & $143(11)$ & $142(16)$ & $146(14)$ \\
Diastolic blood pressure $(\mathrm{mmHg})$ & $80(6)$ & $83(11)$ & $79(10)$ \\
\hline
\end{tabular}

Table 2 Performance data of the participants through the study period

\begin{tabular}{|c|c|c|c|c|c|c|c|c|c|}
\hline & \multicolumn{3}{|c|}{ INT $(N=20)$} & \multicolumn{3}{|c|}{$\mathrm{CON}(N=20)$} & \multicolumn{3}{|c|}{ ANOVA $p$ values $\left(\eta_{\mathrm{p}}^{2}\right)$} \\
\hline & Pre & Post & Follow-up & Pre & Post & Follow-up & Group & Time & Group $\times$ time \\
\hline $\begin{array}{l}\text { COP path length } \\
(\mathrm{mm})\end{array}$ & $1,064(134)$ & $985(165)$ & $899(141)$ & $1,154(251)$ & $1,195(268)$ & $1,151(263)$ & $0.005(0.19)$ & $<0.001(0.17)$ & $0.002(0.15)$ \\
\hline $\begin{array}{l}\text { Beam balancing } 3 \mathrm{~cm} \\
(n)\end{array}$ & $9.2(6.4)$ & $12.8(6.1)$ & $14.4(5.2)$ & $11.3(6.3)$ & $11.1(5.3)$ & $13.3(6.1)$ & $0.88(<0.001)$ & $<0.001(0.21)$ & $0.047(0.08)$ \\
\hline $\begin{array}{l}\text { Beam balancing } \\
4.5 \mathrm{~cm}(n)\end{array}$ & $14.7(6.5)$ & $16.9(6.5)$ & $19.9(4.9)$ & $14.3(6.4)$ & $17.5(5.9)$ & $18.2(5.2)$ & $0.76(0.003)$ & $<0.001(0.27)$ & $0.44(0.02)$ \\
\hline Jump height (cm) & $35.0(5.3)$ & $35.8(5.8)$ & $35.0(4.9)$ & 34.1 (5.4) & $34.1(5.7)$ & $34.3(5.5)$ & $0.50(0.01)$ & $0.62(0.01)$ & $0.50(0.02)$ \\
\hline
\end{tabular}

Data as means with standard deviations (in brackets)

INT intervention group, $C O N$ control group, $n$ total number (of 3 trials) of consecutive backward steps without touching the ground, $\eta_{\mathrm{p}}^{2}$ partial eta squared effect size

beam was notably improved after the intervention period in the training group, and this effect was maintained through the follow-up period. It might be hypothesized that-after familiarization-balancing on the $4.5-\mathrm{cm}$ beam was not demanding enough for construction workers who are used to balance on planks. But during a more difficult balancing situation on a narrower beam, training effects became apparent. On narrow planks, the risk of falling is likely higher, and thus, a stable balance while walking/balancing in such situations, particularly when attention is additionally focused on work, might be crucial to avoid harmful or fatal falls (Pan et al. 2009; Simeonov et al. 2011).

It has been shown that balance training has also the potential to improve lower leg explosive power (Gruber and Gollhofer 2004; Heitkamp et al. 2001). Similarly, Granacher et al. (2011b) observed improvements in various strength measures after an 8-week neuromuscular exercise intervention in the middle-aged workforce. In contrast, we found no such adaptation in jump performance. These different findings might be attributed to the amount of daily exercise duration which was $60 \%$ longer $(3 \times 8 \mathrm{~min}$ each day) in the latter study. Moreover, baseline performance of the construction workers in our study was nearly $10 \%$ higher than in the group of office workers studied by Granacher et al. (2011b). Thus, the potential for further adaptations might be lower in the construction workers of our study. In addition, we only tested for jump performance. Other studies used also laboratory parameters obtained on isometric/isokinetic dynamometers (Granacher et al. 2011b; Gruber and Gollhofer 2004; Heitkamp et al. 2001). Such equipment might allow for more exact and sophisticated determination of strength abilities, and thus, small but relevant changes might be more likely detectable.

Study limitations

Some limitations need to be addressed. First, the nonrandomized allocation of the participants must be mentioned. This might have led to a systematic bias. However, we observed no relevant differences at baseline between groups and thus both groups might be regarded similarly representative of the target population. In addition, we accounted for potential baseline differences in our statistical analysis. The high dropout rate is also a limitation potentially causing a systematic bias as missing training success might facilitate dropout. As training, however, was conducted at the workplace and dropouts did not relevantly differ from analyzed participants in all obtained parameters, a systematic bias seems unlikely. The dropout is in particular relevant with regard to the regular 
Table 3 Absolute and percentage change differences between groups (positive values in favor of intervention group (INT) as compared to control group (CON), adjusted for baseline differences) together with
$90 \%$ confidence intervals $(90 \% \mathrm{CI})$ as well as the probability for an effect being practically beneficial

\begin{tabular}{|c|c|c|c|c|}
\hline & $\begin{array}{l}\text { Absolute change } \\
\text { difference }[90 \% \mathrm{CI}]\end{array}$ & $\begin{array}{l}\text { Standardized mean } \\
\text { difference }[90 \% \mathrm{CI}]\end{array}$ & $\begin{array}{l}\text { Percentage change } \\
\text { difference }[90 \% \mathrm{CI}]\end{array}$ & $\begin{array}{l}\text { Probability for the effect } \\
\text { being practically beneficial }\end{array}$ \\
\hline \multicolumn{5}{|c|}{ COP path length (mm) } \\
\hline Pre to post & $128[55 ; 201]$ & $0.65[0.29 ; 1.00]$ & $11.5 \%[5.4 ; 17.2]$ & $98 \%$; very likely \\
\hline Pre to follow-up & $176[103 ; 249]$ & $0.92[0.55 ; 1.29]$ & $16.9 \%[9.9 ; 21.6]$ & $100 \%$; most likely \\
\hline \multicolumn{5}{|c|}{ Beam balancing $3 \mathrm{~cm}(n)$} \\
\hline Pre to post & $3.0[0.6 ; 5.4]$ & $0.59[0.24 ; 0.94]$ & $57.9 \%[20.5 ; 106.9]$ & $97 \%$; very likely \\
\hline Pre to follow-up & $2.3[-0.2 ; 4.8]$ & $0.40[0.07 ; 0.73]$ & $36.5 \%[5.9 ; 75.9]$ & $86 \%$; likely \\
\hline \multicolumn{5}{|c|}{ Beam balancing $4.5 \mathrm{~cm}(n)$} \\
\hline Pre to post & $-0.8[-3.6 ; 2.0]$ & $-0.15[-0.44 ; 0.14]$ & $-9.4 \%[-25.3 ; 9.9]$ & $3 \%$; unclear \\
\hline Pre to follow-up & $1.5[-0.8 ; 3.8]$ & $0.08[-0.20 ; 0.37]$ & $5.6 \%[-12.7 ; 27.6]$ & $26 \%$; possibly \\
\hline \multicolumn{5}{|l|}{ Jump height (cm) } \\
\hline Pre to post & $0.8[-0.7 ; 2.4]$ & $0.16[-0.13 ; 0.44]$ & $2.6 \%[-2.0 ; 7.3]$ & $42 \%$; possibly \\
\hline pre to follow-up & $0.0[-1.3 ; 1.3]$ & $0.01[-0.23 ; 0.26]$ & $0.2 \%[-3.6 ; 4.2]$ & $11 \%$; unclear \\
\hline
\end{tabular}

implementation of such programs in working routines. It was difficult to perform the exercises and tests regularly with all participants due to organizational constraints, changes in group composition, illness, or occupational obligations. Reports on the adherence to exercise intervention programs in elderly also showed low adherence, although results were partly conflicting (Kohler et al. 2012; McPhate et al. 2013; Simek et al. 2012). Adherence was related to program-related factors (e.g., support, intervention duration, session frequency, and training content) that may be adapted to increase compliance to such programs in the future. However, attendance during the 13-week intervention period was acceptable. Fifty percent of the dropouts occurred during follow-up.

We decided a priori to perform as per protocol analysis, and this study should be regarded as a proof-of-principle. The present study shows that, if neuromuscular training is regularly conducted, relevant beneficial effects can be achieved. The routine implementation of such a neuromuscular intervention must be addressed in future research. Short detraining periods, however, do not seem to be harmful with regard to balance adaptations. Finally, it should be mentioned that we applied only a small number of field tests to assess balance and jump performance. The assessment of postural sway on force plates is a well-established procedure (Donath et al. 2012), and beam balancing can be regarded as an easy and economical test to assess functional balance performance (Donath et al. 2013; Puder et al. 2011). With regard to explosive power, however, isometric dynamometry might be regarded superior as compared to the measurement of jump height. However, this would have required laboratory equipment and was not feasible in the present study. In this regard, it has also to be mentioned that not all investigators were blinded with regard to group allocation.

\section{Conclusions and perspectives}

To the best of our knowledge, this was the first study which analyzed the effects of a specific neuromuscular training program on selected fall risk factors for construction workers. We conclude that a neuromuscular training program at the worksite lasting $15 \mathrm{~min}$ each day can relevantly improve balance performance in middle-aged construction workers and, thus, may contribute to a decreased fall risk in this population. Training adaptations with regard to balance performance can be maintained at least 8 weeks after the intervention was terminated. However, in light of the pilot character and the limitations of this study, the results and conclusions should be regarded preliminary and further confirmation is required. Moreover, as the dropout rate was high, it is warranted to evaluate adaptations to the program which may allow for a higher adherence in the long term. The implementation of such exercise programs in working routines is a challenge for the future and the potential to effectively reduce falls on construction sites should be evaluated in large-scale randomized controlled trials. Possibly, exercise-based prevention may supplement standard educational guidelines and safety technologies to increase the effectiveness of fall prevention and, thus, to contribute to a safer workplace for construction workers.

Acknowledgments The study was supported by the Swiss National Accidence Insurance Fund (Schweizerische Unfallversicherungsanstalt-SUVA, Luzern, Switzerland). The authors gratefully 
acknowledge the support of Edith Müller and Sandra Mathis from SUVA as well as the Implenia AG (Aarau, Switzerland) for their help in recruiting the participants. In addition, we thank all workers and their foremen for the good compliance.

Conflict of interest The authors declare that they have no conflict of interest.

\section{References}

Batterham AM, Hopkins WG (2006) Making meaningful inferences about magnitudes. Int J Sports Physiol Perform 1(1):50-57

Bentley TA, Haslam RA (2001) Identification of risk factors and countermeasures for slip, trip and fall accidents during the delivery of mail. Appl ergon 32(2):127-134

Chi CF, Chang TC, Ting HI (2005) Accident patterns and prevention measures for fatal occupational falls in the construction industry. Appl ergon 36(4):391-400. doi:10.1016/j.apergo.2004.09.011

Coren S (1993) The lateral preference inventory for measurement of handedness, footedness, eyedness, and earedness: norms for young adults. Bull Psychon Soc 31(1):1-3

Courtney TK, Sorock GS, Manning DP, Collins JW, Holbein-Jenny MA (2001) Occupational slip, trip, and fall-related injuriescan the contribution of slipperiness be isolated? Ergonomics 44(13):1118-1137. doi:10.1080/00140130110085538

Donath L, Roth R, Zahner L, Faude O (2012) Testing single and double limb standing balance performance: comparison of COP path length evaluation between two devices. Gait Posture S09666362(12):00120-00128. doi:10.1016/j.gaitpost.2012.04.001

Donath L, Roth R, Rueegge A, Groppa M, Zahner L, Faude O (2013) Effects of slackline training on balance, jump performance and muscle activity in young children. Int J Sports Med 34(12):10931098. doi:10.1055/s-0033-1337949

Faude O, Kellmann M, Ammann T, Schnittker R, Meyer T (2011) Seasonal changes in stress indicators in high level football. Int $\mathrm{J}$ Sports Med 32(4):259-265. doi:10.1055/s-0030-1269894

Frey I, Berg A, Keul J (1995) Assessment and evaluation of leisure activity of participants in heart rehabilitation groups. Wien Klin Wochenschr 107(24):774-777

Gauchard G, Chau N, Mur JM, Perrin P (2001) Falls and working individuals: role of extrinsic and intrinsic factors. Ergonomics 44(14):1330-1339. doi:10.1080/00140130110084791

Gillespie LD, et al. (2012) Interventions for preventing falls in older people living in the community. Cochrane Database Syst Rev 9:CD007146 doi:10.1002/14651858.CD007146.pub3

Granacher U, Gollhofer A, Strass D (2006) Training induced adaptations in characteristics of postural reflexes in elderly men. Gait Posture 24(4):459-466. doi:10.1016/j.gaitpost.2005.12.007

Granacher U, Muehlbauer T, Zahner L, Gollhofer A, Kressig RW (2011a) Comparison of traditional and recent approaches in the promotion of balance and strength in older adults. Sports Med 41(5):377-400. doi:10.2165/11539920-000000000-00000

Granacher U, Wick C, Rueck N, Esposito C, Roth R, Zahner $\mathrm{L}$ (2011b) Promoting balance and strength in the middleaged workforce. Int $\mathrm{J}$ Sports Med 32(1):35-44. doi:10.105 5/s-0030-1267214

Gruber M, Gollhofer A (2004) Impact of sensorimotor training on the rate of force development and neural activation. Eur J Appl Physiol 92(1-2):98-105. doi:10.1007/s00421-004-1080-y

Heitkamp HC, Horstmann T, Mayer F, Weller J, Dickhuth HH (2001) Gain in strength and muscular balance after balance training. Int $\mathbf{J}$ Sports Med 22(4):285-290. doi:10.1055/s-2001-13819

Hewett TE, Lindenfeld TN, Riccobene JV, Noyes FR (1999) The effect of neuromuscular training on the incidence of knee injury in female athletes. A prospective study. Am J Sports Med 27(6):699-706

Hopkins WG (2006) Analysis of a pre-post controlled trial (Excel spreadsheet). newstats.org/xParallelGroupTrial.xls. In. http://ww w.sportsci.org Accessed 10 February 2012

Hopkins WG, Marshall SW, Batterham AM, Hanin J (2009) Progressive statistics for studies in sports medicine and exercise science. Med Sci Sports Exerc 41(1):3-13. doi:10.1249/MSS.0b013e318 $18 \mathrm{cb} 278$

Hsiao H, Simeonov P (2001) Preventing falls from roofs: a critical review. Ergonomics 44(5):537-561. doi:10.1080/00140130110034480

Hübscher M, Zech A, Pfeifer K, Hansel F, Vogt L, Banzer W (2010) Neuromuscular training for sports injury prevention: a systematic review. Med Sci Sports Exerc 42(3):413-421. doi:10.1249/MSS. 0b013e3181b88d37

Kiers H, van Dieen J, Dekkers H, Wittink H, Vanhees L (2013) A systematic review of the relationship between physical activities in sports or daily life and postural sway in upright stance. Sports Med 43(11):1171-1189. doi:10.1007/s40279-013-0082-5

Kohler A, Kressig RW, Schindler C, Granacher U (2012) Adherence rate in intervention programs for the promotion of physical activity in older adults: a systematic literature review. Praxis 101(24):1535-1547. doi:10.1024/1661-8157/a001129

Leamon TB, Murphy PL (1995) Occupational slips and falls: more than a trivial problem. Ergonomics 38(3):487-498. doi:10.1080/00140139508925120

Lipscomb HJ, Glazner JE, Bondy J, Guarini K, Lezotte D (2006) Injuries from slips and trips in construction. Appl ergon 37(3):267274. doi:10.1016/j.apergo.2005.07.008

McPhate L, Simek EM, Haines TP (2013) Program-related factors are associated with adherence to group exercise interventions for the prevention of falls: a systematic review. J physiother 59(2):8192. doi:10.1016/S1836-9553(13)70160-7

Meeuwisse WH (1994) Assessing causation in sport injury: a multifactorial model. Clin J Sport Med 4:166-170

Min SN, Kim JY, Parnianpour M (2012) The effects of safety handrails and the heights of scaffolds on the subjective and objective evaluation of postural stability and cardiovascular stress in novice and expert construction workers. Appl ergon 43(3):574-581. doi:10.1016/j.apergo.2011.09.002

Muehlbauer T, Gollhofer A, Granacher U (2011) Relationship between measures of balance and strength in middle-aged adults. J Strength Cond Res. doi:10.1519/JSC.0b013e31823f8c41

Orr R (2010) Contribution of muscle weakness to postural instability in the elderly. A systematic review. Eur J Phys Rehabil Med 46(2): $183-220$

Pan CS, Chiou S, Kau TY, Bhattacharya A, Ammons D (2009) Effects of foot placement on postural stability of construction workers on stilts. Appl ergon 40(4):781-789. doi:10.1016/j.apergo.2008.08.003

Papegaaij S, Taube W, Baudry S, Otten E, Hortobagyi T (2014) Aging causes a reorganization of cortical and spinal control of posture. Frontiers Aging Neurosci 6:28. doi:10.3389/fnagi.2014.00028

Puder JJ et al (2011) Effect of multidimensional lifestyle intervention on fitness and adiposity in predominantly migrant preschool children (Ballabeina): cluster randomised controlled trial. BMJ 343:d6195. doi:10.1136/bmj.d6195

Redfern MS et al (2001) Biomechanics of slips. Ergonomics 44(13):1138-1166. doi:10.1080/00140130110085547

Risberg MA, Mork M, Jenssen HK, Holm I (2001) Design and implementation of a neuromuscular training program following anterior cruciate ligament reconstruction. J Orthop Sports Phys Ther 31(11):620-631. doi:10.2519/jospt.2001.31.11.620

Simek EM, McPhate L, Haines TP (2012) Adherence to and efficacy of home exercise programs to prevent falls: a systematic review and meta-analysis of the impact of exercise program characteristics. Prev Med 55(4):262-275. doi:10.1016/j.ypmed.2012.07.007 
Simeonov P, Hsiao H, Powers J, Ammons D, Kau T, Amendola A (2011) Postural stability effects of random vibration at the feet of construction workers in simulated elevation. Appl ergon 42(5):672-681. doi:10.1016/j.apergo.2010.10.002

Taube W, Kullmann N, Leukel C, Kurz O, Amtage F, Gollhofer A (2007) Differential reflex adaptations following sensorimotor and strength training in young elite athletes. Int $\mathrm{J}$ Sports Med 28(12):999-1005. doi:10.1055/s-2007-964996

Taube W, Gruber M, Gollhofer A (2008) Spinal and supraspinal adaptations associated with balance training and their functional relevance. Acta Physiol (Oxf) 193(2):101-116. doi:10.1111/j. 1748-1716.2008.01850.x

Thomas S, Reading J, Shephard RJ (1992) Revision of the Physical Activity Readiness Questionnaire (PAR-Q). Can J Sport Sci 17(4):338-345

Tuunainen E, Rasku J, Jantti P, Pyykko I (2013) Risk factors of falls in community dwelling active elderly. Auris Nasus Larynx. doi:10.1016/j.anl.2013.05.002 van der Molen HF, et al. (2012) Interventions to prevent injuries in construction workers. Cochrane Database Syst Rev 12:CD006251 doi:10.1002/14651858.CD006251.pub3

Verhagen EA, Bay K (2010) Optimising ankle sprain prevention: a critical review and practical appraisal of the literature. Br J Sports Med 44(15):1082-1088. doi:10.1136/bjsm.2010.076406

Warner M, Barnes PM, Fingerhut LA (2000) Injury and poisoning episodes and conditions: National Health Interview Survey, 1997. Vital and health statistics Series 10, Data from the National Health Survey(202):1-38

Young WB, Pryor JF, Wilson GJ (1995) Effect of instructions on characteristics of countermovement and drop jump performance. J Strength Cond Res 9(4):232-236

Zech A, Hubscher M, Vogt L, Banzer W, Hansel F, Pfeifer K (2010) Balance training for neuromuscular control and performance enhancement: a systematic review. J Athl Train 45(4):392-403. doi:10.4085/1062-6050-45.4.392 